\title{
Comparative Efficacy and Safety of Peficitinib Versus Tofacitinib and Baricitinib for Treatment of Rheumatoid Arthritis: A Systematic Review and Network Meta-Analysis
}

\author{
Yoshiya Tanaka $\cdot$ Hiroyuki Okumura $\cdot$ Soyoung Kim · Julie Dorey • \\ Piotr Wojciechowski · Justyna Chorąży • Daisuke Kato • \\ Neil M. Schultz
}

Received: December 4, 2020 / Accepted: January 23, 2021 / Published online: March 16, 2021

(c) The Author(s) 2021

\section{ABSTRACT}

Introduction: Peficitinib, a Janus kinase (JAK) inhibitor, is approved for clinical use in Japan, Korea, and Taiwan, but head-to-head comparisons versus other JAK inhibitors are lacking. We indirectly compared peficitinib, tofacitinib, and baricitinib for rheumatoid arthritis treatment.

Methods: We searched MEDLINE, Embase, the Cochrane Central Register of Controlled Trials,

Supplementary Information The online version contains supplementary material available at https:// doi.org/10.1007/s40744-021-00284-1.

Y. Tanaka $(\bowtie)$

The First Department of Internal Medicine, School of Medicine, University of Occupational and Environmental Health, Japan, Kitakyushu, Japan e-mail: tanaka@med.uoeh-u.ac.jp

H. Okumura · D. Kato

Astellas Pharma Inc., Tokyo, Japan

S. Kim

Astellas Pharma Singapore Pte. Ltd, Singapore,

Singapore

J. Dorey

Creativ-Ceutical, Paris, France

P. Wojciechowski · J. Chorąży

Creativ-Ceutical, Krakow, Poland

N. M. Schultz

Astellas Pharma Global Development, Inc.,

Northbrook, USA
ClinicalTrials.gov, and congress archives up until February 12, 2019, for randomized controlled trials of peficitinib, tofacitinib, and baricitinib. Efficacy (American College of Rheumatology responses, disease activity scores, modified total Sharp score, Simplified Disease Activity Index [SDAI]) and safety outcomes were compared using a Bayesian network meta-analysis. The Preferred Reporting Items for Systematic reviews and Meta-Analyses (PRISMA) consensus was followed for reporting results. A network meta-regression assessed the impact on outcomes of proportions of patients receiving concomitant methotrexate or of Asian ethnicity.

Results: The network meta-analysis included 21 randomized controlled trials. At 12 weeks, all evaluable efficacy outcomes were comparable or improved with peficitinib $150 \mathrm{mg}$ and $100 \mathrm{mg}$ once daily, versus baricitinib 2 and $4 \mathrm{mg}$ once daily and tofacitinib $5 \mathrm{mg}$ twice daily. At 24 weeks, efficacy outcomes were comparable or improved for each peficitinib dose versus baricitinib and tofacitinib. Risk of adverse events and serious adverse events at 12 weeks were similar with peficitinib 100 and $150 \mathrm{mg}$ versus baricitinib and tofacitinib. The proportion of patients receiving concomitant methotrexate had no effect on any outcome analyzed, but Asian ethnicity had a positive effect on multiple efficacy outcomes.

Conclusions: Peficitinib had comparable efficacy versus tofacitinib and baricitinib for 
reduction in disease activity as measured by SDAI, and for reduction in progression of joint damage as measured radiographically. No notable differences in safety outcomes were observed. Further studies are required to better characterize the impact of ethnicity on the efficacy of JAK inhibitors.

Keywords: Baricitinib; Janus kinase inhibitor; Network meta-analysis; Peficitinib; Systematic literature review; Tofacitinib

\section{Key Summary Points}

Why carry out this study?

Peficitinib, a Janus kinase (JAK) inhibitor, has demonstrated efficacy and tolerability for the treatment of rheumatoid arthritis in Asian patients; however, head-to-head clinical trials comparing peficitinib with other JAK inhibitors are lacking.

We conducted a systematic literature review and network meta-analysis of randomized controlled trials to indirectly compare the efficacy and safety of peficitinib, tofacitinib, and baricitinib.

What was learned from this study?

Peficitinib (100 and $150 \mathrm{mg}$ once daily) provided comparable or improved efficacy outcomes versus tofacitinib (5 mg twice daily) and baricitinib ( 2 or $4 \mathrm{mg}$ once daily).

Safety of peficitinib, as measured by rates of adverse events and serious adverse events, was comparable to both tofacitinib and baricitinib.

For each of these JAK inhibitors versus placebo, Asian ethnicity was associated with a positive effect on multiple efficacy outcomes.

\section{DIGITAL FEATURES}

This article is published with digital features, including summary slide, to facilitate understanding of the article. To view digital features for this article go to https://doi.org/10.6084/ m9.figshare.13626134.

\section{INTRODUCTION}

Rheumatoid arthritis (RA) is a chronic autoimmune disease characterized primarily by inflammation of the joint synovial membranes, but it can also manifest as vascular, bone, metabolic, and psychological disorders $[1,2]$. As the goal of RA treatment is to achieve sustained remission or low disease activity (LDA), diseasemodifying antirheumatic drugs (DMARDs) form the backbone of treatment regimens [3]. The recommended first-line therapies are conventional synthetic DMARDs (csDMARDs), primarily methotrexate (MTX); for patients who do not achieve sustained remission or LDA after 6 months, the csDMARD can be switched, or used in combination with a biologic DMARD or a targeted synthetic DMARD (tsDMARD) [3, 4].

Janus kinase (JAK) inhibitors are tsDMARDs that target the JAK family of tyrosine kinases (JAK1, JAK2, JAK3, and tyrosine kinase 2) [5]. JAKs transduce inflammatory cytokine signals from the cell membrane to the nucleus and are consequently implicated in the pathogenesis of RA [5]. At the time of this research, JAK inhibitors licensed for use (in any country) were tofacitinib [6], baricitinib [6], and peficitinib [7]; more recently, upadacitinib has also received approval [8].

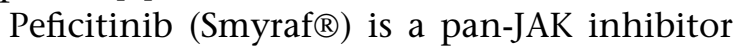
[7] that has demonstrated efficacy in phase 3 trials in Asia $[9,10]$, with a similar safety profile to other JAK inhibitors [7, 11]. It is approved for clinical use in Japan, Korea, and Taiwan, and is in late-stage clinical development in other Asian countries [7, 12, 13]. Tofacitinib (Xeljanz $\left.{ }^{\circledR}\right)$ is an inhibitor of the JAK family that preferentially inhibits JAK1 and/or JAK3 over JAK2 $[6,14]$, while baricitinib (Olumiant $\AA$ ) is an inhibitor of JAK1 and JAK2 [15]. Both tofacitinib and baricitinib have shown efficacy and 
tolerability in global phase 3 trials and are licensed for use in multiple countries worldwide $[16,17]$.

There is a lack of head-to-head clinical trials between currently available JAK inhibitors. Some indirect comparisons between JAK inhibitors [18-26], or between different peficitinib doses [27], have been reported, but these included only a restricted selection of efficacy and safety outcomes and/or did not investigate between-study heterogeneity. The aim of our research was to indirectly compare peficitinib versus tofacitinib and baricitinib for the treatment of patients with RA, over a broad range of clinical efficacy, structural, and safety outcomes.

\section{METHODS}

\section{Search Strategy and Selection Criteria}

A systematic literature review was conducted on February 12, 2019, to identify randomized controlled trials (RCTs) assessing the efficacy and/or safety of peficitinib, tofacitinib, or baricitinib in patient populations with RA and a history of DMARD use (Fig. 1). The Preferred Reporting Items for Systematic reviews and Meta-Analyses (PRISMA) consensus was followed for reporting results [28]. Databases included were MEDLINE, Embase, the Cochrane Central Register of Controlled Trials, and the ClinicalTrials.gov trial registry. The archives of the American College of Rheumatology (ACR)/ Association of Rheumatology Health Professionals (now the Association of Rheumatology Professionals) Annual Meetings were also searched (from inception via Ovid, with an additional manual search to capture the 2018 meeting records).

RCTs with a parallel design and comparable follow-up period were included; real-world studies, letters, comments, case reports, editorials, in vitro or animal studies, and systematic reviews were excluded. Also excluded from the database search were conference abstracts prior to 2016 and studies after completion of phase 3 . No other restrictions on language, date or geographical scope were applied. In addition to information available in the public domain, clinical study reports from peficitinib trials were obtained to supplement any missing information. Searches were conducted according to the Participants, Interventions, Comparisons, Outcome, Study design (PICOS) statement [28], and a list of search terms used is provided in Supplementary file 1 .

Following the identification of potential publications to be included, they were assessed to ascertain if multiple articles related to the same study; any systematic reviews identified from the searches were retrieved and their list of references screened for all potential sources of evidence. Duplicate results were removed; studies on DMARD-naïve patients were also excluded at this stage. Two independent reviewers conducted the study screening and identification. Any disagreements were resolved through discussion with a third reviewer. The methodological quality of the included studies was assessed using the Cochrane risk of bias tool [29]. Data extraction was conducted by one reviewer and validated by a second reviewer.

This article is based on previously conducted studies and does not contain any new studies with human participants or animals performed by any of the authors.

\section{Interventions and Outcomes}

The interventions studied were peficitinib (100 mg once daily, $150 \mathrm{mg}$ once daily; as monotherapy or in combination with MTX); tofacitinib (5 mg twice daily, $11 \mathrm{mg}$ once daily; as monotherapy or in combination with MTX); and baricitinib ( $2 \mathrm{mg}$ once daily, $4 \mathrm{mg}$ once daily; as monotherapy or in combination with MTX). Only interventions approved for clinical use were eligible and tofacitinib $10 \mathrm{mg}$ twice daily was thus excluded from the network, given that this dose is not recommended for use in patients with RA [30, 31]. For studies where MTX was used concomitantly with JAK inhibitors, this requirement was applied across all treatment arms, including those with placebo comparators.

The following efficacy outcomes were analyzed for weeks 12 and 24 timepoints: 


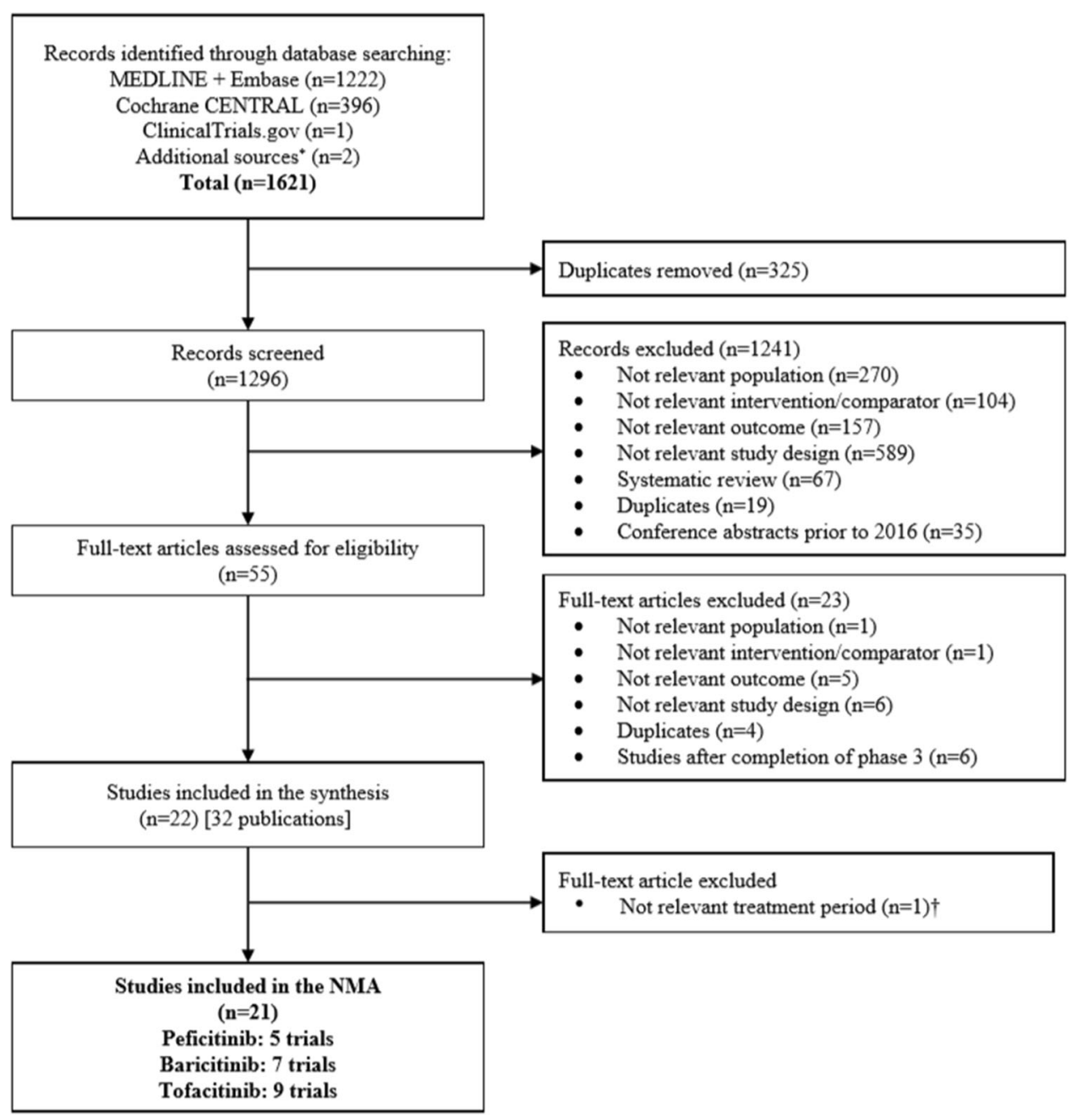

Fig. 1 Study selection flow chart. ${ }^{*}$ Conference abstracts submitted to 2018 American College of Rheumatology/ Association of Rheumatology Health Professionals Annual Meeting in Chicago (https://acrabstracts.org/meetings/ 2018-acr-arhp-annual-meeting/). $\dagger$ The phase 2 a study of

percentage of patients with ACR20/50/70 response; 28-joint disease activity score using C-reactive protein (DAS28-CRP) and using erythrocyte sedimentation rate (DAS28-ESR); the percentage of patients achieving DAS28-CRP/ESR $<2.6$ and $\leq 3.2$; change from baseline in van der Heijde-modified total Sharp score (mTSS); percentage of patients with change from baseline in mTSS $\leq 0.5$; Simplified Disease Activity Index (SDAI) score; and percentage of patients with $\mathrm{SDAI} \leq 3.3$. Safety outcomes analyzed were the overall incidence of adverse tofacitinib by Kremer JM et al. Arthritis Rheum 2009 was omitted from the NMA and NMR due to its 6-week treatment period. Cochrane CENTRAL the Cochrane Central Register of Controlled Trials, NMA network meta-analysis, $N M R$ network meta-regression

events (AEs) and incidence of serious adverse events (SAEs). Where available, data for the intention-to-treat (ITT) population were preferred over other analysis sets.

\section{Data Analysis}

An indirect treatment comparison between peficitinib and baricitinib or tofacitinib was conducted using a Bayesian network metaanalysis (NMA) plus a network meta-regression (NMR) to test the robustness of data after 
adjusting for between-trial differences in baseline characteristics, in accordance with guidance from The UK National Institute for Health and Care Excellence (NICE) and the International Society for Pharmacoeconomics and Outcomes Research (ISPOR) [32-35].

\section{Network Meta-Analysis}

Clinical data were pooled using both fixed- and random-effects models (Supplementary file 2). Studies with a follow-up of 9-15 weeks were pooled together to define a 12-week network; similarly, studies with a follow-up of 20-30 weeks were pooled together to define a 24-week network. For studies that included patients initially assigned to placebo and then switched to active treatment, only the period prior to switching was included.

For binary outcomes (expressed as the odds of an ACR20/50/70 response; remission as defined by DAS28-CRP/-ESR $<2.6$ and SDAI $\leq 3.3$; LDA as defined by DAS28-CRP/-ESR $\leq 3.2$; and experiencing an $\mathrm{AE}$ or $\mathrm{SAE}$ ), between-treatment differences were compared using posterior medians of odds ratios (OR) with 95\% credibility intervals (CrI). For continuous variables (changes from baseline in DAS28CRP/-ESR, SDAI and mTSS), posterior medians of between-treatment differences with 95\% CrI were reported. The surface under the cumulative ranking curve (SUCRA) was calculated for each outcome and treatment.

\section{Network Meta-Regression}

An NMR was conducted to assess the impact of between-study heterogeneity on the magnitude of the relative effect versus the comparator arm, in accordance with the NICE Decision Support Unit guidelines (Supplementary file 3) [33]. The potential covariates investigated were the mean percentage of patients receiving concomitant MTX and the mean percentage of Asian patients, in each study (Table 1). For outcomes with a confirmed interaction between percentage of patients receiving MTX and magnitude of the effect, the mean dose of MTX in each study was also tested as a covariate. NMA models were preferred over NMR models unless the deviance information criterion (DIC) for the NMR model was lower by $\geq 5$ points, indicating a meaningfully better fit.

\section{RESULTS}

\section{Study Screening and Inclusion}

A total of 1296 unduplicated records were identified (Fig. 1). Full-text analysis was conducted for 55 articles, and 22 RCTs (from 32 publications) were included in an initial synthesis. Of these, one study of tofacitinib (Kremer 2009) [36] was excluded as the treatment period was only 6 weeks. The remaining 21 trials (five peficitinib, seven baricitinib, and nine tofacitinib) had assessed JAK inhibitors for $\geq 12$ weeks, reported relevant outcomes, and were included in the meta-analysis (Table 1). No RCTs assessing tofacitinib $11 \mathrm{mg}$ once daily were identified.

The included studies were published between 2011 and 2019, with the number of patients per study ranging from 55 to 975 ; the total number of patients included in the NMA was 6542 (Table 1). The network of studies included in efficacy and safety comparisons is given in Fig. 2. For all included studies, the risk of bias in relation to method of treatment allocation and outcome reporting was judged to be low to unclear across all domains (Supplementary file 4 ).

\section{NMA Results}

All evaluable efficacy outcomes were significantly improved with both peficitinib 100 and $150 \mathrm{mg}$ compared with placebo (Tables 2 and 3; Supplementary file 5). At 12 weeks, all evaluable efficacy outcomes were comparable or improved with peficitinib $150 \mathrm{mg}$ versus baricitinib 2 or $4 \mathrm{mg}$ and tofacitinib $5 \mathrm{mg}$ (Table 2; Supplementary file 5). The efficacy of peficitinib $150 \mathrm{mg}$ was significantly improved versus tofacitinib $5 \mathrm{mg}$ for the proportion of patients achieving DAS28-ESR $\leq 3.2$ (OR [95\% CrI] 2.46 $[1.10,5.58])$; versus baricitinib $2 \mathrm{mg}$ regarding ACR50 response (OR [95\% CrI] 1.63 [1.04, 


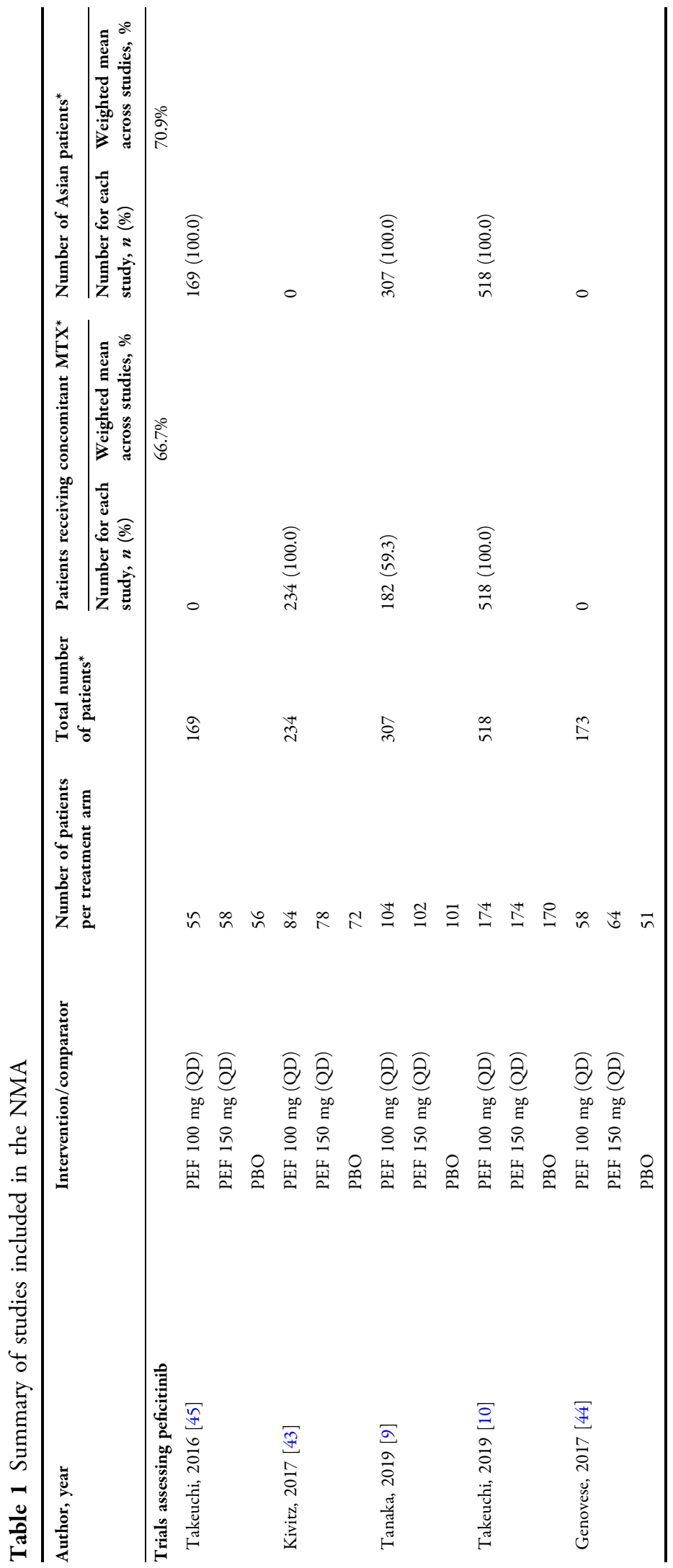




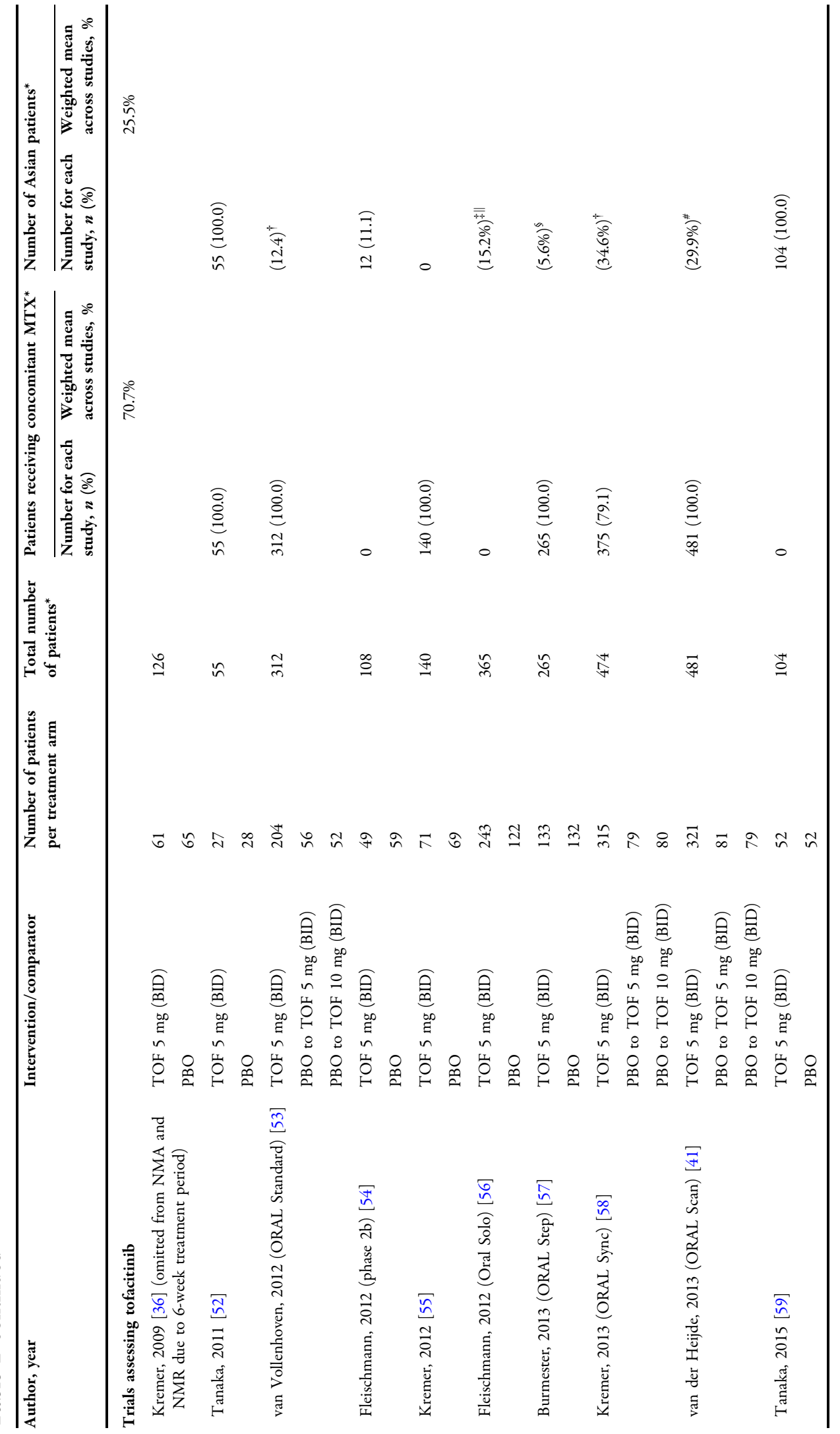




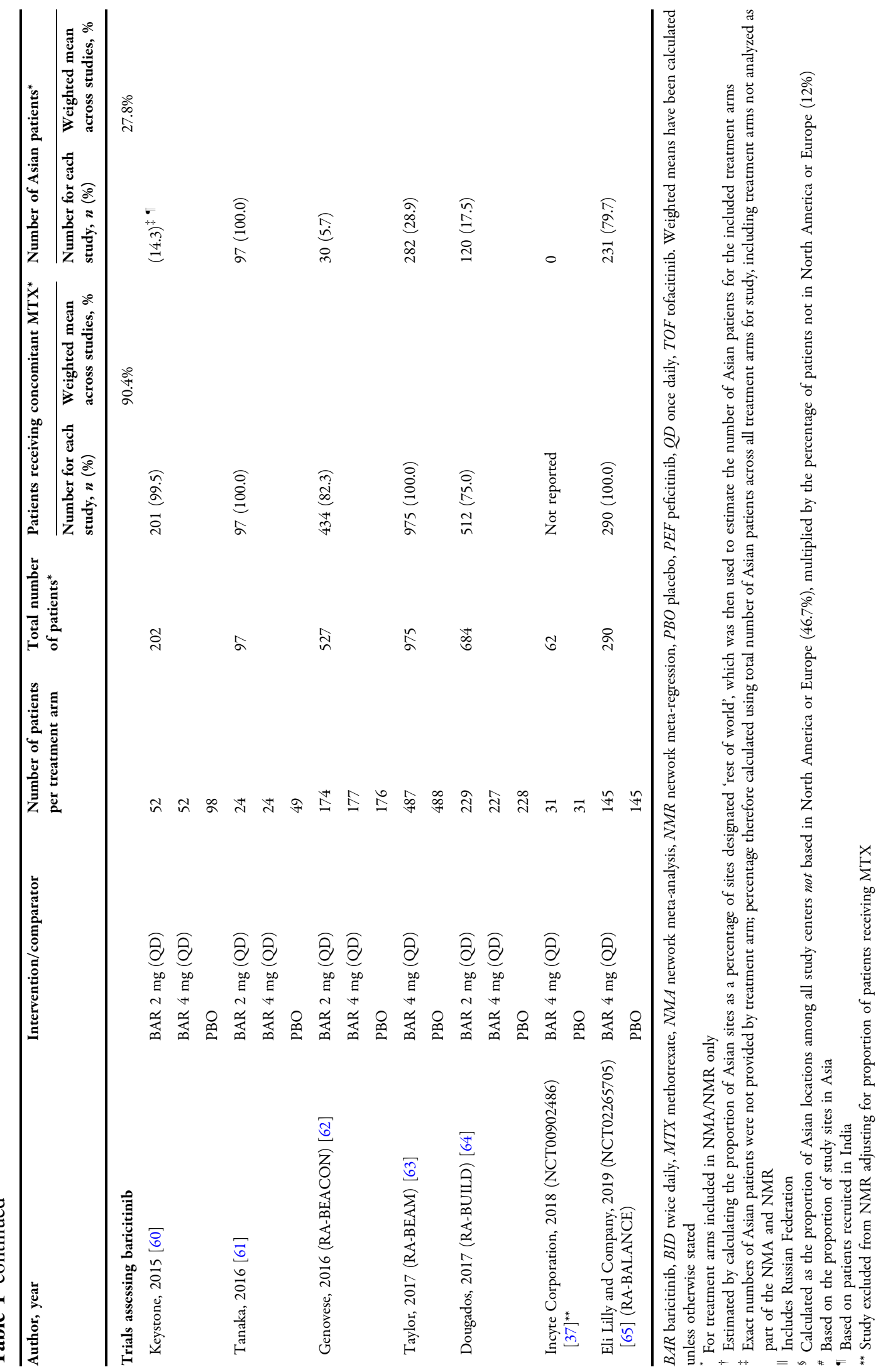




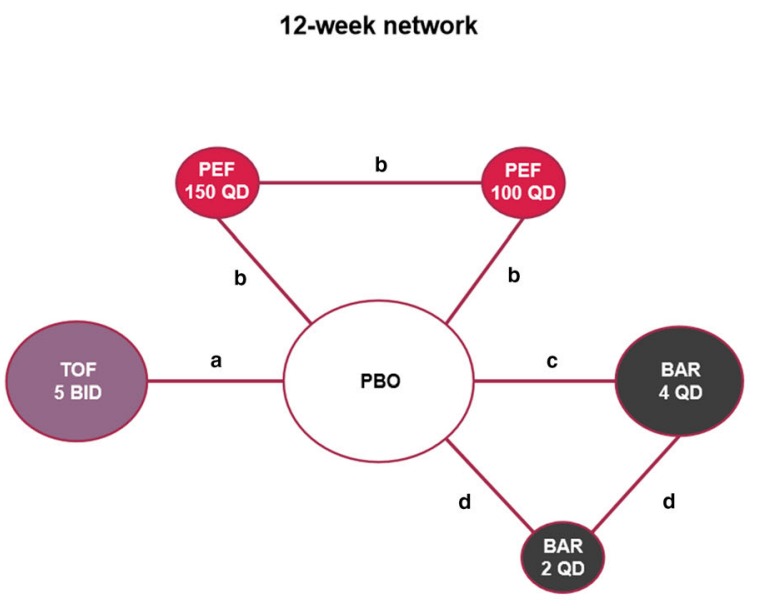

Fig. 2 Network of eligible comparisons for efficacy and safety of JAK inhibitors for RA. a Tanaka, 2011; van Vollenhoven, 2012; Fleischmann, 2012 (ph 2b); Kremer, 2012; Fleischmann, 2012 (Oral Solo); Burmester, 2013; van der Heijde, 2013; Tanaka, 2015. b Takeuchi, 2016; Kivitz, 2017; Tanaka, 2019; Takeuchi, 2019; Genovese, 2017. c Keystone, 2015; Tanaka, 2016; Genovese, 2016; Taylor, 2017; Dougados, 2017; Incyte Co., 2018; Eli Lilly and Co., 2019. d Keystone, 2015; Tanaka, 2016; Genovese, 2016; Dougados, 2017. e Fleischmann, 2012 (ph 2b); van Vollenhoven, 2012; Kremer, 2012; Kremer,

2.58]); and versus baricitinib 2 and $4 \mathrm{mg}$ for reductions in SDAI score (OR [95\% CrI] - 7.02 $[-9.76,-4.32]$ and $-4.48[-6.97,-1.98]$, respectively), achievement of $\mathrm{SDAI} \leq 3.3$ (OR [95\% CrI] $7.79[1.56,115.30]$ and $6.42[1.34$, 92.81], respectively), achievement of DAS28$\mathrm{CRP} \leq 3.2(\mathrm{OR}$ [95\% CrI] 2.94 [1.83, 4.79] and $2.02[1.31,3.18]$, respectively), and achievement of DAS28-ESR $\leq 3.2$ (OR [95\% CrI] 3.07 $[1.59,6.24]$ and $2.42[1.31,4.77]$, respectively) (Table 2; Supplementary file 5). At 12 weeks, peficitinib $100 \mathrm{mg}$ was comparable to baricitinib 2 or $4 \mathrm{mg}$ and tofacitinib $5 \mathrm{mg}$ for almost all efficacy outcomes analyzed; peficitinib $100 \mathrm{mg}$ provided significant improvement versus baricitinib $2 \mathrm{mg}$ for reductions in SDAI score (OR [95\% CrI] - $2.82[-5.58,-0.08]$ ) and the proportion of patients achieving DAS-CRP $\leq 3.2$ (OR [95\% CrI] 1.96 [1.22, 3.21]) (Table 3; Supplementary file 5). SUCRA rankings indicated that patients receiving peficitinib $150 \mathrm{mg}$ were the most likely to achieve ACR20 or ACR50 response at 12 weeks, followed by

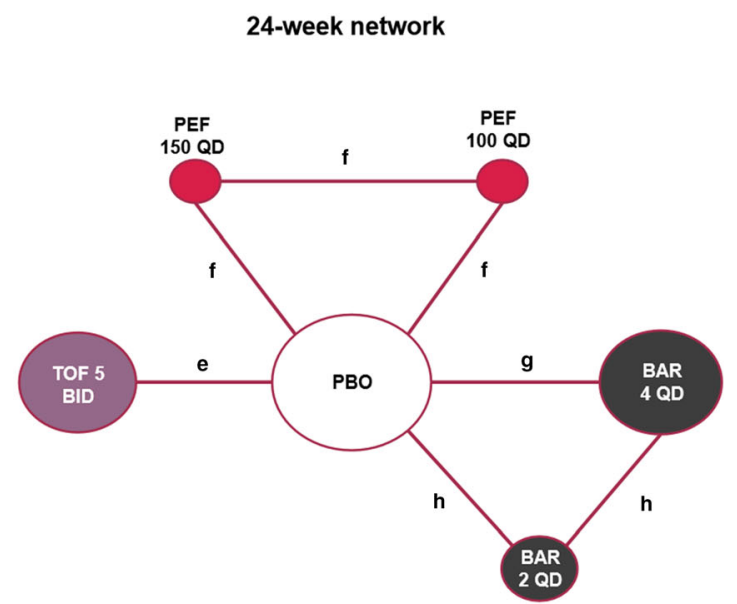

2013; van der Heijde, 2013. f Takeuchi, 2019. g Genovese, 2016; Taylor, 2017; Dougados, 2017; Eli Lilly and Co., 2019. h Genovese, 2016; Dougados, 2017. The size of each treatment node is proportional to the number of randomized patients, assumes all studies are included; the number of patients may differ for specific outcomes. $B A R$ baricitinib, $B I D$ twice daily, $J A K$ Janus kinase, $P B O$ placebo, $P E F$ peficitinib, $Q D$ once daily, $R A$ rheumatoid arthritis, RCT randomized controlled trial, $T O F$ tofacitinib

tofacitinib $5 \mathrm{mg}$, baricitinib $4 \mathrm{mg}$, peficitinib $100 \mathrm{mg}$, baricitinib $2 \mathrm{mg}$, and placebo (Supplementary file 5). However, for ACR70 response at 12 weeks, baricitinib 2 and $4 \mathrm{mg}$ were ranked above peficitinib $150 \mathrm{mg}$ (Supplementary file 5).

At 24 weeks, all efficacy outcomes were comparable or improved with either peficitinib 150 or $100 \mathrm{mg}$ versus baricitinib 2 or $4 \mathrm{mg}$ and tofacitinib $5 \mathrm{mg}$ (Tables 2 and 3; Supplementary file 6). ACR20 response, ACR50 response, and change from baseline in mTSS were improved with either peficitinib dose compared with baricitinib 2 or $4 \mathrm{mg}$ and tofacitinib $5 \mathrm{mg}$ (Tables 2 and 3; Supplementary file 6). Peficitinib 100 or $150 \mathrm{mg}$ also provided significant improvement over tofacitinib $5 \mathrm{mg}$ for change in DAS28-CRP scores and over baricitinib $2 \mathrm{mg}$ for achievement of DAS28-CRP $\leq 2.6$ (Tables 2 and 3; Supplementary file 6). Change from baseline in DAS28-CRP scores and achievement of mTSS $\leq 0.5$ were also significantly improved with peficitinib $150 \mathrm{mg}$, but not peficitinib 
738

Rheumatol Ther (2021) 8:729-750

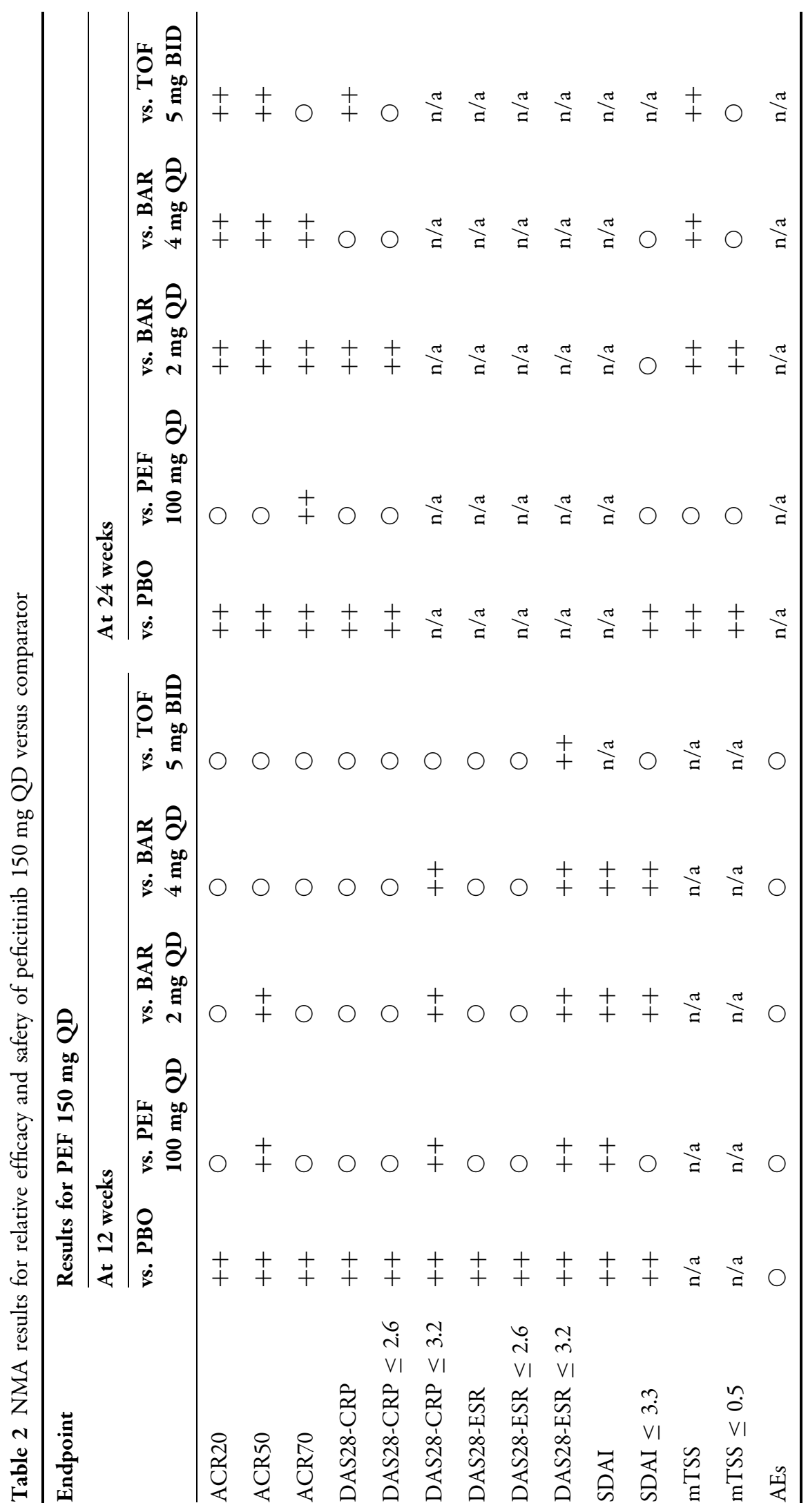

$\triangle$ Adis 


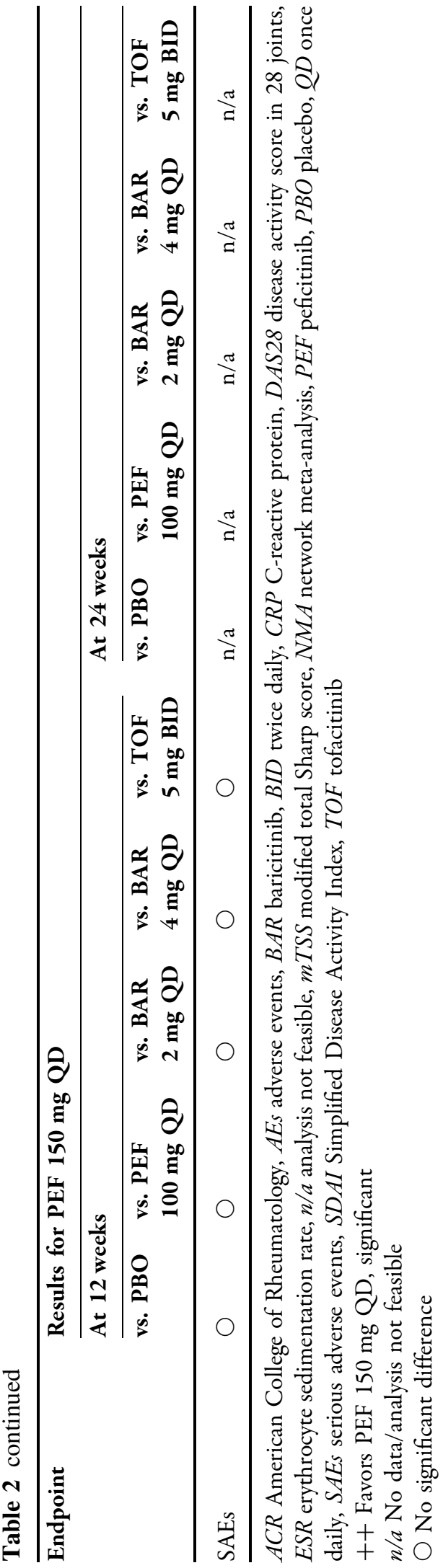

$100 \mathrm{mg}$, over baricitinib $2 \mathrm{mg}$ (Tables 2 and 3; Supplementary file 6). The highest SUCRA ranking for ACR20 and ACR50 responses at 24 weeks was achieved by peficitinib $150 \mathrm{mg}$, followed by peficitinib $100 \mathrm{mg}$, baricitinib $4 \mathrm{mg}$, tofacitinib $5 \mathrm{mg}$, baricitinib $2 \mathrm{mg}$, and placebo (Supplementary file 6). This ranking differed for ACR70 at 24 weeks, for which tofacitinib $5 \mathrm{mg}$ ranked higher than did peficitinib $100 \mathrm{mg}$ (Supplementary file 6). It was not possible to evaluate change from baseline in SDAI at 24 weeks due to a scarcity of data.

For safety outcomes, both peficitinib doses were comparable to placebo, baricitinib 2 or $4 \mathrm{mg}$, and tofacitinib $5 \mathrm{mg}$ regarding the risk of AEs and SAEs at 12 weeks (Tables 2 and 3; Supplementary file 5). Due to a lack of data, it was not possible to evaluate risk of AEs and SAEs at 24 weeks.

NMA results by study are presented in Supplementary files 5 and 6 .

\section{NMR Results}

\section{Adjustment for Percentage of Patients Receiving MTX}

Of the 21 studies included in the NMA, one study (Incyte Corporation 2018 [37]) was excluded from the estimation of the mean percentage of patients receiving concomitant MTX as it did not report this information (Table 1). Across the remaining studies, the weighted mean percentage of patients receiving MTX was 67,67 , and $90 \%$ for studies of peficitinib, tofacitinib, and baricitinib, respectively (Table 1). For all efficacy and safety analyses, there was no evidence for interaction between the percentage of patients receiving MTX and the magnitude of the treatment effect (Table 4). The analysis adjusting for mean MTX dose was therefore not performed.

The results of the NMA and NMR were consistent except for the comparisons of peficitinib $150 \mathrm{mg}$ versus tofacitinib for achievement of DAS28-ESR $\leq 3.2$ at week 12; peficitinib $150 \mathrm{mg}$ versus baricitinib $2 \mathrm{mg}$ for achievement of DAS28-CRP $\leq 2.6$ at week 24 ; and peficitinib $100 \mathrm{mg}$ versus baricitinib $2 \mathrm{mg}$ for achievement of DAS28-CRP $\leq 2.6$ at week 24 (Supplementary 


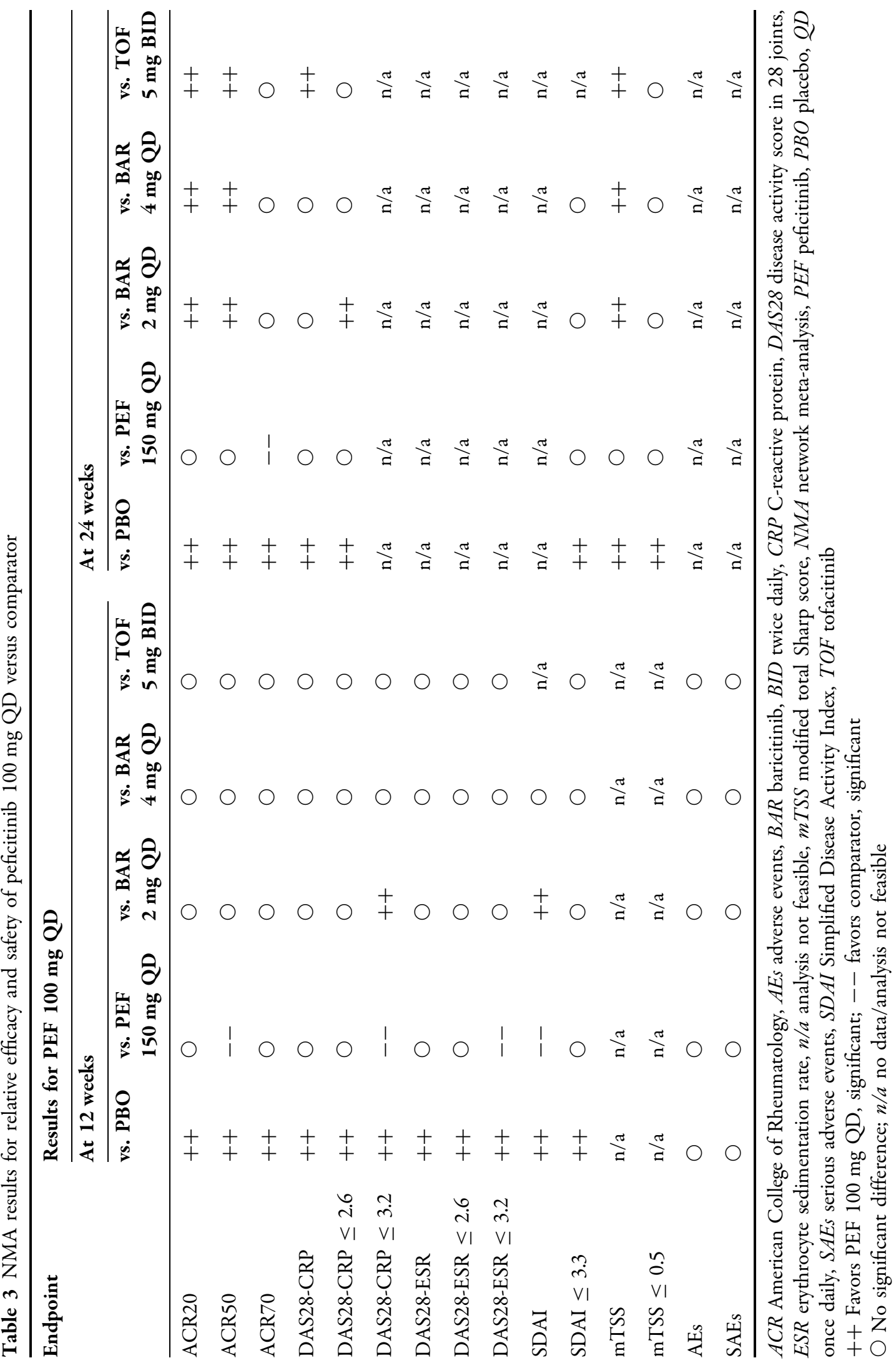




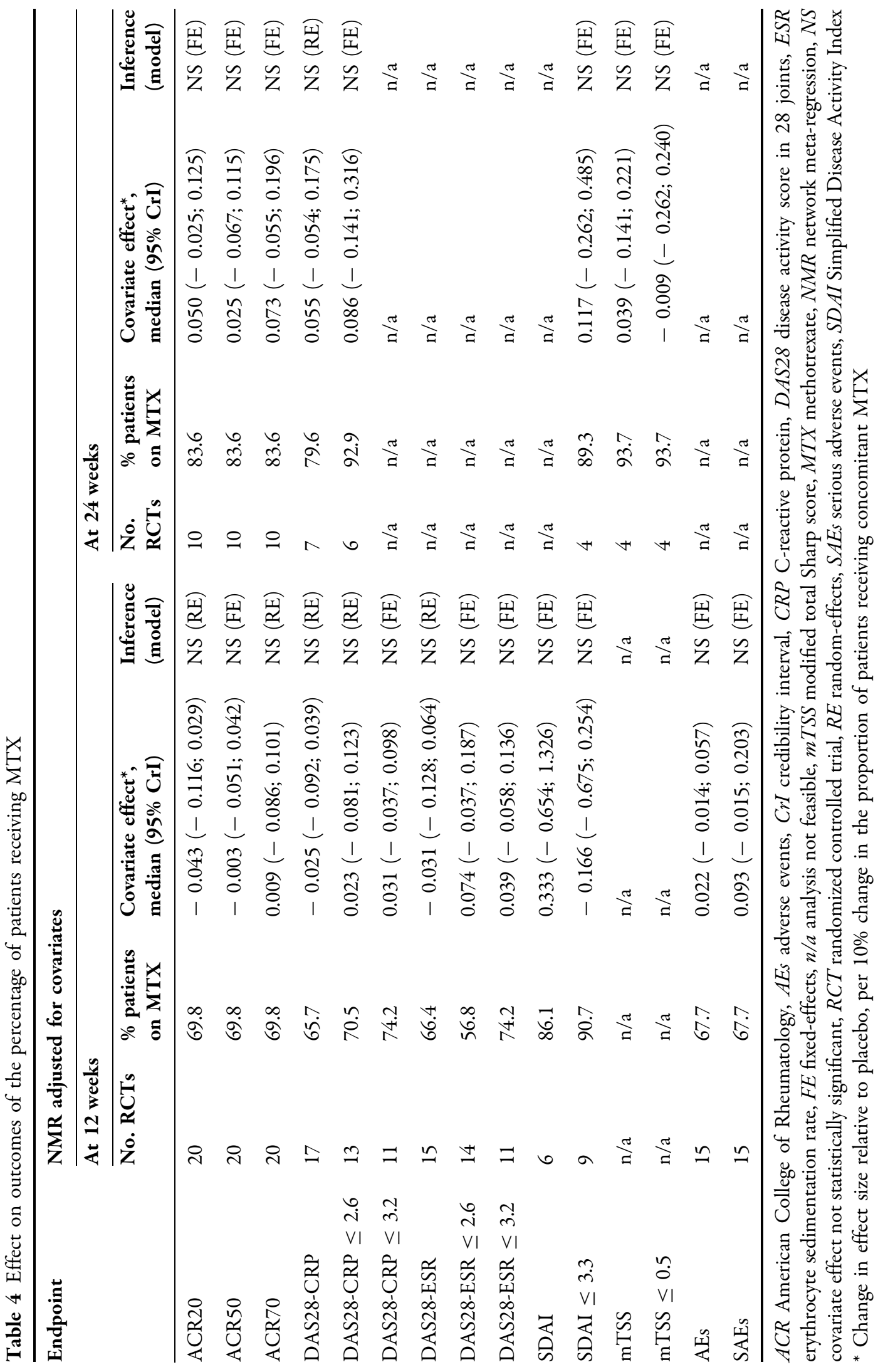


files 7 and 8). The NMA was preferred over the NMR for all efficacy and safety comparisons, taking into account model simplicity, DIC values, and the reduced number of studies included in the NMR (Supplementary file 9).

\section{Adjustment for Percentage of Asian Patients}

All 21 studies were included in the estimation of the mean percentage of Asian patients. The weighted mean percentage of Asian patients was 71,23 , and $28 \%$ for studies of peficitinib, tofacitinib, and baricitinib, respectively (Table 1). A relationship between the percentage of Asian patients and the magnitude of treatment effect was observed for ACR20/50/70 responses, achievement of DAS28-ESR $\leq 3.2$, and change in SDAI at week 12; and ACR50 response and mean change in DAS28-CRP at week 24 (Table 5). For all other efficacy and safety outcomes, the percentage of Asian patients had no significant effect (Table 5).

For the majority of outcomes, the NMA model was preferred based on lower DIC values, with the exception of ACR20/50/70 responses at week 12 (Supplementary files 10-12). The NMR models for ACR50 response and change in DAS28-CRP at week 24 had numerically lower DIC values; however, the magnitude of the difference was not considered meaningful and the simpler NMA model was preferred for these outcomes (Supplementary files 10 and 11).

Following adjustment for the percentage of Asian patients, the results of the NMR indicated that changes from baseline in mTSS at week 24 were not significant for peficitinib 100 and $150 \mathrm{mg}$ versus baricitinib 2 and $4 \mathrm{mg}$ or tofacitinib (Supplementary files 10 and 11). When compared with placebo, only peficitinib $150 \mathrm{mg}$ showed significant improvement for change from baseline in mTSS at week 24, after adjustment for the percentage of Asian patients (Supplementary files 10 and 11).

\section{DISCUSSION}

This NMA demonstrated that peficitinib (100 and $150 \mathrm{mg}$ once daily) was comparable to, and in some cases provided significant improvement over, tofacitinib (5 mg twice daily) and baricitinib ( 2 or $4 \mathrm{mg}$ once daily) for control of disease symptoms (as measured by ACR20/50/ 70 responses), reduction of inflammatory states (DAS28-CRP and -ESR scores), and reduction in the rate of disease progression (mTSS and SDAI). Based on SUCRA rankings, peficitinib $150 \mathrm{mg}$ had the highest probability of being the best treatment in terms of ACR20 response at both 12 and 24 weeks in the populations studied. Notably, both doses of peficitinib were associated with significantly improved rates of ACR20/50 responses and reduction of change from baseline in mTSS after 24 weeks of treatment, compared with tofacitinib and baricitinib. However, between-treatment differences in the proportion of patients achieving changes from baseline in mTSS of $\leq 0.5$ were not significant except for peficitinib $150 \mathrm{mg}$ versus baricitinib $2 \mathrm{mg}$. Of note, as extended-release tofacitinib $11 \mathrm{mg}$ once daily is approved for use in the USA, this dose of tofacitinib was considered eligible for inclusion in the NMA and NMR; however, no RCTs assessing this regimen were identified and tofacitinib $11 \mathrm{mg}$ therefore could not be included in our comparisons. It should also be highlighted that our NMA results did not take into account between-trial differences in baseline characteristics, which were instead analyzed in our subsequent NMR.

Our findings are broadly consistent with a previously published NMA comparing JAK inhibitors as monotherapy, which found that peficitinib $150 \mathrm{mg}$ had significantly greater odds of achieving an ACR20 response at 12 to 24 weeks versus tofacitinib $5 \mathrm{mg}$ and baricitinib $4 \mathrm{mg}$ [26]. In contrast, an NMA of JAK inhibitors in combination with DMARDs ranked tofacitinib $10 \mathrm{mg}+$ MTX above peficitinib $150 \mathrm{mg}+$ MTX for ACR20 response at 12 to 24 weeks; however, the between-treatment differences in ACR20 response rates did not reach significance in this study [25]. Moreover, in our NMR, ACR20 responses were comparable between peficitinib $150 \mathrm{mg}$ versus tofacitinib $5 \mathrm{mg}$ and baricitinib 2 or $4 \mathrm{mg}$ after adjustment for the proportion of Asian patients.

Encouragingly, our results showed that rates of AEs and SAEs for both peficitinib 100 and $150 \mathrm{mg}$ were comparable to other JAK inhibitors and to placebo. A number of other previous 


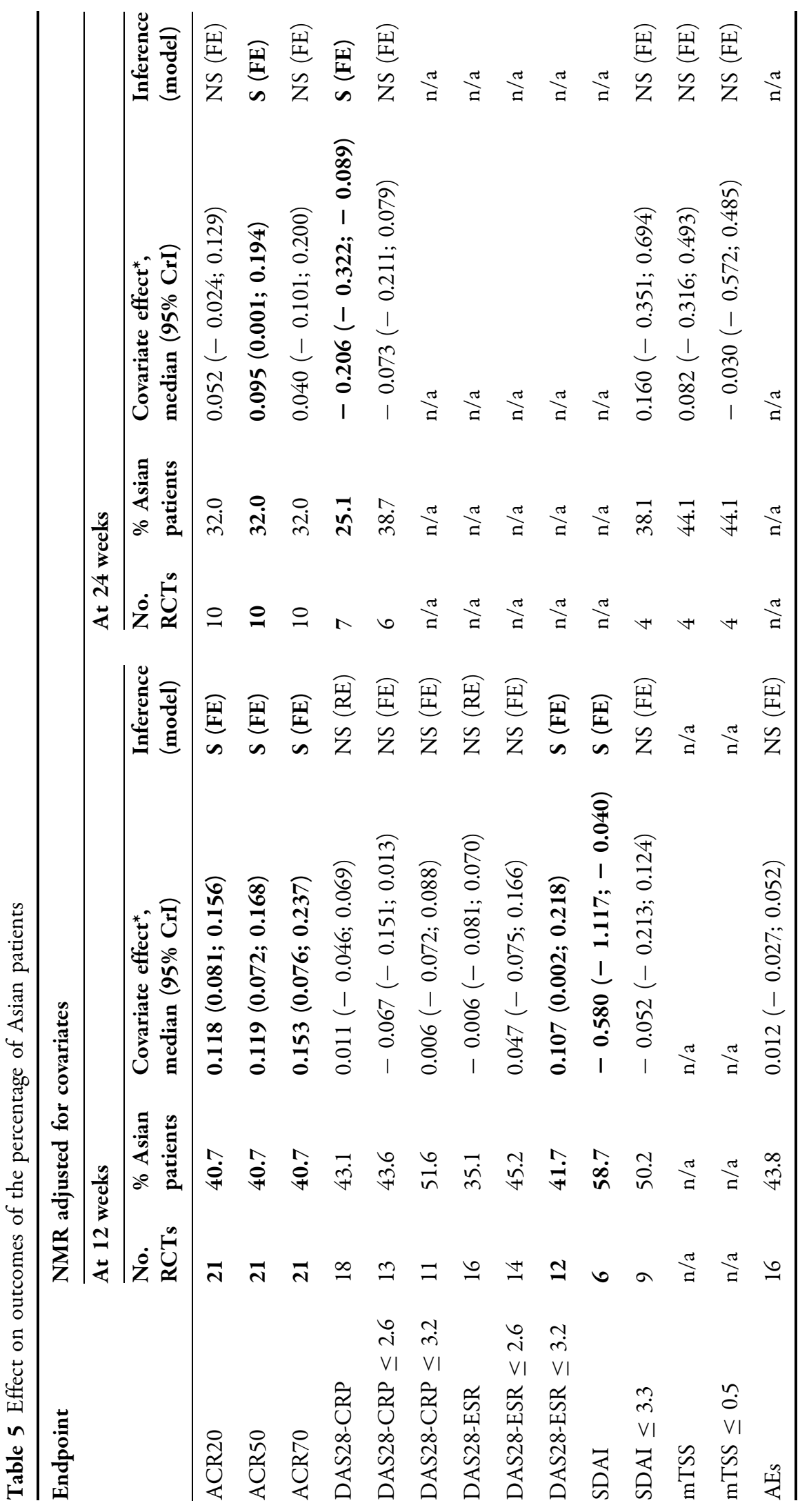




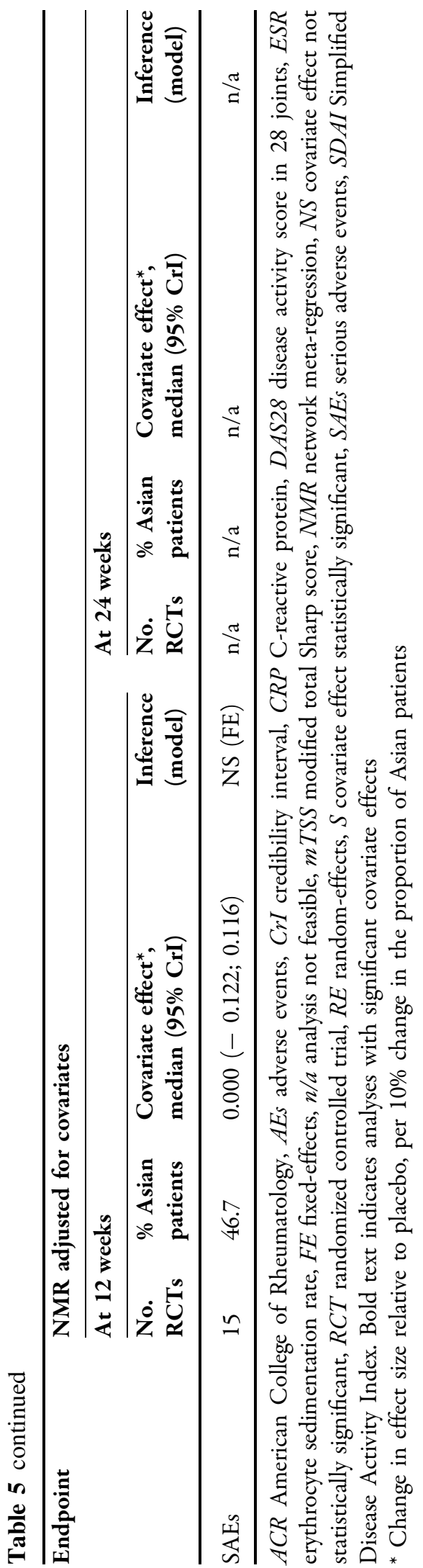

analyses have also found the rate of SAEs to be not significantly different between peficitinib and tofacitinib [25], peficitinib and baricitinib [26], and between tofacitinib, baricitinib, and peficitinib versus placebo $[19,25,26,38,39]$; an exception was for tofacitinib $5 \mathrm{mg}$ as monotherapy, which was associated with a significantly lower rate of SAEs versus peficitinib $100 \mathrm{mg}$, baricitinib $4 \mathrm{mg}$, and placebo [26]. It should also be highlighted that an increased rates of herpes zoster-related disease (which was not assessed in our study) has been observed with JAK inhibitor treatment $[39,40]$. We note, however, that these NMAs are not directly comparable due to differences in included interventions, methodology, and patient populations.

According to our NMR analyses, there was no evidence of an interaction between MTX and any of the efficacy and safety outcomes assessed. However, Asian ethnicity was associated with a positive effect on ACR20/50/70 responses, change from baseline in SDAI score, and the proportion of patients achieving DAS28-ESR $\leq 3.2$ at week 12; and ACR50 response and change from baseline in DAS28-CRP score at week 24 . This positive effect was observed with peficitinib, tofacitinib, and baricitinib. A greater beneficial effect of JAK inhibitors versus placebo was observed in studies with a higher proportion of Asian patients.

A notable finding from the current NMA was that some efficacy outcomes were improved with peficitinib (100 and $150 \mathrm{mg}$ once daily) compared with tofacitinib (5 $\mathrm{mg}$ twice daily) and baricitinib ( 2 or $4 \mathrm{mg}$ once daily): after 24 weeks of treatment, these included ACR20 response, ACR50 response, and change from baseline in mTSS. This may be the result of the relatively higher proportion of Asian patients in the peficitinib clinical trials than in tofacitinib and baricitinib trials; due to the interaction between Asian ethnicity and the responses listed in the previous paragraph, the relative efficacy of peficitinib versus the other two JAK inhibitors was reduced once analyses were adjusted for the percentage of Asian patients. These results are consistent with data from previous trials, which showed that tofacitinib had greater efficacy in Asian patients than in 
patients of other ethnicities, for unknown reasons $[41,42]$. We have also observed that peficitinib performed better in clinical trials in patients in Asian countries $[9,10]$ compared with those in a global trial reported by Kivitz et al. [43], despite the fact that patients in all three trials had had an inadequate response to MTX, and also predominantly moderate-tosevere RA according to baseline DAS28 or other validated composite measures of disease activity $[9,10,43]$. On the other hand, the findings of the Kivitz et al. study could be attributed to the high placebo effect in the study population ( $44 \%$ of placebo-treated patients had an ACR20 response at 12 weeks); this effect also showed large variability depending on region, and sensitivity analyses including only European centers did indicate superiority of peficitinib over placebo [43]. Similarly, patients in the Genovese et al. trial also had a high ACR20 response rate with placebo treatment (22\% at 12 weeks); despite this, ACR20 response rates at 12 weeks with peficitinib were significantly higher at $48-56 \%$ for the total study population [44]. These relatively high placebo responses in non-Asian patients contrast with the average ACR20 response rates at 12 weeks of $11-31 \%$ among Asian patients who received placebo, across the phase 2 and phase 3 trials $[9,10,45]$. Further investigations are needed to elucidate the reasons underlying the interethnic differences observed in these trials.

Our research fills an important gap in this area by including peficitinib, one of the more recently approved JAK inhibitors and available only in some East Asian countries, in an indirect comparison with the globally available products tofacitinib and baricitinib. Strengths of our NMA include the assessment of multiple efficacy outcomes at both week 12 and week 24 timepoints; the inclusion of both AEs and SAEs in the analysis; and its conduct in line with ISPOR and NICE guidelines. Furthermore, we conducted an NMR analysis to enable us to assess the impact of between-study heterogeneity, regarding both concomitant MTX use and Asian ethnicity, on our findings. One limitation of this NMA and NMR is that the number of studies assessing outcomes at 24 weeks was lower than the number assessing outcomes at 12 weeks; in particular, safety outcomes were assessed only for the week 12 timepoint, as safety data for the peficitinib phase 3 studies were available only at weeks 12 and $52[9,10]$ and no SDAI data were available for comparisons at week 24. Furthermore, the literature review identified studies published up to February 2019, which is when our analyses were conducted, and we recognize that more recent studies have been omitted. Additionally, we did not compare the risk of AEs of special interest in RA patient populations: namely, serious infections, herpes zoster-related disease, and malignancy. Studies also allowed for cross-over from placebo to JAK inhibitor after 12-24 weeks owing to lack of efficacy and the ethical issue of long-term placebo treatment. Different methods were often adopted to account for missing data arising from either between-treatment cross-over and/or loss to follow-up. With regard to remission and LDA, our analyses defined these outcomes as scores of $<2.6$ and $\leq 3.2$, respectively, for both DAS28-CRP and DAS28ESR; however, DAS28-CRP has been shown not to be interchangeable with DAS28-ESR based on the same cut-off thresholds [46].

The patients included in our analyses were predominantly those with a history of prior DMARD use, and our analyses may not extrapolate to patients who are DMARD-naïve. However, given current EULAR (European League Against Rheumatism) and APLAR guidelines $[4,47]$, patients who have had prior DMARD use are likely to be the target patient population for JAK inhibitors. For the NMR, covariate values (the percentage of patients receiving concomitant MTX and the percentage of Asian patients) were not adequately reported across all identified studies; this was particularly the case regarding the proportions of Asian patients and, for many RCTs, these values were estimated based on the location of study centers, which increases uncertainty of the outcomes. Furthermore, the high proportion of Asian patients in peficitinib studies may have adversely affected the NMR adjustment.

The analysis of mTSS at 24 weeks was based on only four trials, and the mean change from baseline observed in the placebo arms was inconsistent across the studies (peficitinib: 3.4; tofacitinib: 0.47 ; baricitinib: $0.7-0.8$ ), 
indicating noticeable between-trial heterogeneity. A further challenge to interpretation of the mTSS findings is posed by differences between studies in baseline MTX dose, particularly as the dose of MTX tends to be lower in Japan than in other countries $[47,48]$, and our analysis did not take into account the average dose that patients received in each study. mTSS scores also tend to be higher in Japanese patients than in other populations [49-51].

\section{CONCLUSIONS}

In conclusion, the results of this study suggest that peficitinib had comparable efficacy versus both tofacitinib and baricitinib for a majority of the outcomes assessed, and no notable differences in safety assessments were observed. Further analyses are required to better characterize efficacy of JAK inhibitors in different ethnicities, which may require going beyond RCTs.

\section{ACKNOWLEDGEMENTS}

Funding. This study was initiated and funded by Astellas Pharma Global Development, Inc. The publication fee was also funded by Astellas Pharma Global Development, Inc. The study sponsor was involved in all stages of the study, including manuscript development. All authors had full access to all study data and agreed to submit the manuscript for publication. No honorarium, grant, or other form of payment was provided to authors, with the exception of funding needed to perform their role in the study. All authors agreed to the provision of professional medical writing support on behalf of the study sponsor.

Medical Writing and/or Editorial Assistance. Medical writing support was provided by Iona Easthope, DPhil, of Cello Health MedErgy (Europe), funded by Astellas Pharma Global Development, Inc.

Authorship. All named authors meet the International Committee of Medical Journal
Editors (ICMJE) criteria for authorship, take responsibility for the integrity of the work as a whole, and have given their approval for this version to be published.

Authorship Contributions. YT, HO, SK and DK were involved in the design of the study and interpretation of the results. JD, PW and JC were involved in the design of the study and the acquisition and analysis of data. NS was involved in the study design, acquisition and analysis of data, and the interpretation of the results. All authors had full access to the study data, contributed to critical revisions of the manuscript for important intellectual content, and approved the final version of the article to be submitted. Medical writing and editorial support were provided by Iona Easthope, DPhil, of Cello Health MedErgy (Europe), under the direction of the authors.

Prior Presentation. These data were presented in part as an oral presentation at the Japan College of Rheumatology 64th Annual Scientific Meeting, 4-6 August 2020, and an abstract including data from this study has been submitted to APLAR 2020.

Disclosures. Yoshiya Tanaka has received speaking fees and/or honoraria from DaiichiSankyo, Eli Lilly, Novartis, YL Biologics, BristolMyers Squibb, Eisai, Chugai, AbbVie, Astellas, Pfizer, Sanofi, Asahi Kasei, GlaxoSmithKline, Mitsubishi-Tanabe, Gilead, and Janssen; and has received research grants from MitsubishiTanabe, Chugai, AbbVie, Takeda, UCB, DaiichiSankyo, and Eisai. Hiroyuki Okumura, Soyoung Kim, Daisuke Kato and Neil M Schultz are employees of Astellas Pharma Inc. Piotr Wojciechowski and Justyna Chorąży are employees of Creativ-Ceutical, a consultancy, which was commissioned by Astellas Pharma Inc. to conduct this analysis. Julie Dorey was an employee of Creativ-Ceutical at the time of this analysis, and is currently an employee of Boehringer Ingelheim.

Compliance with Ethics Guidelines. This article is based on previously conducted studies and does not contain any new studies with 
human participants or animals performed by any of the authors.

Data Availability. Researchers may request access to anonymized participant-level data, trial-level data, and protocols from Astellassponsored clinical trials at www. clinicalstudydatarequest.com. For the Astellas criteria on data sharing see: https:// clinicalstudydatarequest.com/Study-Sponsors/ Study-Sponsors-Astellas.aspx.

Open Access. This article is licensed under a Creative Commons Attribution-NonCommercial 4.0 International License, which permits any non-commercial use, sharing, adaptation, distribution and reproduction in any medium or format, as long as you give appropriate credit to the original author(s) and the source, provide a link to the Creative Commons licence, and indicate if changes were made. The images or other third party material in this article are included in the article's Creative Commons licence, unless indicated otherwise in a credit line to the material. If material is not included in the article's Creative Commons licence and your intended use is not permitted by statutory regulation or exceeds the permitted use, you will need to obtain permission directly from the copyright holder. To view a copy of this licence, visit http://creativecommons.org/licenses/by$\mathrm{nc} / 4.0 /$.

\section{REFERENCES}

1. Smolen JS, Aletaha D, McInnes IB. Rheumatoid arthritis. Lancet. 2016;388:2023-38.

2. McInnes IB, Schett G. Pathogenetic insights from the treatment of rheumatoid arthritis. Lancet. 2017;389:2328-37.

3. Smolen JS, Landewé R, Bijlsma J, Burmester G, Chatzidionysiou K, Dougados $\mathrm{M}$, et al. EULAR recommendations for the management of rheumatoid arthritis with synthetic and biological diseasemodifying antirheumatic drugs: 2016 update. Ann Rheum Dis. 2017;76:960-77.

4. Lau CS, Chia F, Dans L, Harrison A, Hsieh TY, Jain $\mathrm{R}$, et al. 2018 update of the APLAR recommendations for treatment of rheumatoid arthritis. Int J Rheum Dis. 2019;22:357-75.

5. Tanaka Y. The JAK inhibitors: do they bring a paradigm shift for the management of rheumatic diseases? Rheumatology. 2019;58:11-3.

6. Jegatheeswaran J, Turk M, Pope JE. Comparison of Janus kinase inhibitors in the treatment of rheumatoid arthritis: a systemic literature review. Immunother Engl. 2019;11:737-54.

7. Tanaka Y, Izutsu H. Peficitinib for the treatment of rheumatoid arthritis: an overview from clinical trials. Expert Opin Pharmacother. 2020;21:1015-25.

8. Duggan S. Keam SJ. Upadacitinib: first approval. Drugs. 2019;79:1819-28.

9. Tanaka Y, Takeuchi T, Tanaka S, Kawakami A, Iwasaki M, Song YW, et al. Efficacy and safety of peficitinib (ASP015K) in patients with rheumatoid arthritis and an inadequate response to conventional DMARDs: a randomised, double-blind, placebo-controlled phase III trial (RAJ3). Ann Rheum Dis. 2019;78:1320-32.

10. Takeuchi T, Tanaka Y, Tanaka S, Kawakami A, Iwasaki M, Katayama K, et al. Efficacy and safety of peficitinib (ASP015K) in patients with rheumatoid arthritis and an inadequate response to methotrexate: results of a phase III randomised, double-blind, placebo-controlled trial (RAJ4) in Japan. Ann Rheum Dis. 2019;78:1305-19.

11. Takeuchi T, Tanaka Y, Tanaka S, Kawakami A, Song Y-W, Chen Y-H, et al. Safety and effectiveness of peficitinib (ASP015K) in patients with rheumatoid arthritis: interim data (22.7 months mean peficitinib treatment) from a long-term, open-label extension study in Japan, Korea, and Taiwan. Arthritis Res Ther. 2020;22:47.

12. Astellas Pharma Taiwan, Inc. Drug details: $50 \mathrm{mg}$ Smyraf (peficitinib hydrobromide) [Internet]. 2020 [cited 2020 Jun 4]. https://info.fda.gov.tw/MLMS/ H0001D.aspx?Type $=$ Lic\&LicId $=52027856$

13. Astellas Pharma Taiwan, Inc. Drug details: $100 \mathrm{mg}$ Smyraf (peficitinib hydrobromide) [Internet]. 2020 [cited 2020 Jun 4]. https://info.fda.gov.tw/MLMS/ H0001D.aspx? Type $=$ Lic\&LicId $=52027857$

14. Dhillon S. Tofacitinib: a review in rheumatoid arthritis. Drugs. 2017;77:1987-2001.

15. Al-Salama ZT, Scott LJ. Baricitinib: a review in rheumatoid arthritis. Drugs. 2018;761-72.

16. Cohen S, Curtis JR, DeMasi R, Chen Y, Fan H, Soonasra A, et al. Worldwide, 3-year, post-marketing surveillance experience with tofacitinib in 
rheumatoid arthritis. Rheumatol Ther. 2018;5: 283-91.

17. van der Heijde D, Schiff M, Tanaka Y, Xie L, Meszaros $G$, Ishii $T$, et al. Low rates of radiographic progression of structural joint damage over 2 years of baricitinib treatment in patients with rheumatoid arthritis. RMD Open. 2019;5:e000898.

18. Song GG, Choi SJ, Lee YH. Comparison of the efficacy and safety of tofacitinib and upadacitinib in patients with active rheumatoid arthritis: a Bayesian network meta-analysis of randomized controlled trials. Int J Rheum Dis. 2019;22:1563-71.

19. Bae SC, Lee YH. Comparison of the efficacy and safety of tofacitinib and baricitinib in patients with active rheumatoid arthritis: a Bayesian network meta-analysis of randomized controlled trials. Z Rheumatol. 2019;78:559-67.

20. Fautrel B, Zhu B, Taylor P, van de Laar M, Emery P, De Leonardis F, et al. Comparative effectiveness of improvement in pain and physical function for baricitinib versus adalimumab, tocilizumab, and tofacitinib monotherapies in rheumatoid arthritis patients who are naïve to treatment with biologic or conventional synthetic disease. RMD Open. 2020;1-10.

21. Lee Y, Song G. Comparative efficacy and safety of tofacitinib, baricitinib, upadacitinib, and filgotinib in active rheumatoid arthritis refractory to biologic disease-modifying antirheumatic drugs. Z Rheumatol. 2020. https://doi.org/10.1007/s00393-02000796-1.

22. Lee YH, Song GG. Comparison of the efficacy and safety of tofacitinib and filgotinib in patients with active rheumatoid arthritis: a Bayesian network meta-analysis of randomized controlled trials. Z Rheumatol. 2019;79:590-603.

23. Lee YH, Song GG. Relative efficacy and safety of tofacitinib, baricitinib, upadacitinib, and filgotinib in comparison to adalimumab in patients with active rheumatoid arthritis. Z Rheumatol. 2020;79: 785-96.

24. Pope J, Sawant R, Tundia N, Du EX, Qi CZ, Song Y, et al. Comparative efficacy of JAK inhibitors for moderate-to-severe rheumatoid arthritis: a network meta-analysis. Adv Ther. 2020;37:2356-72.

25. Lee YH, Song GG. Comparison of the efficacy and safety of tofacitinib and peficitinib in patients with active rheumatoid arthritis: a Bayesian network meta-analysis of randomized controlled trials. Int J Rheum Dis. 2020;23:868-75.

26. Lee YH, Song GG. Comparative efficacy and safety of tofacitinib, baricitinib, upadacitinib, filgotinib and peficitinib as monotherapy for active rheumatoid arthritis. J Clin Pharm Ther. 2020;45:674-81.

27. Lee YH, Song GG. Comparative efficacy and safety of peficitinib 25, 50, 100, and $150 \mathrm{mg}$ in patients with active rheumatoid arthritis: a Bayesian network meta-analysis of randomized controlled trials. Clin Drug Investig. 2020;40:65-72.

28. Liberati A, Altman DG, Tetzlaff J, Mulrow C, Gøtzsche PC, Ioannidis JPA, et al. The PRISMA statement for reporting systematic reviews and meta-analyses of studies that evaluate healthcare interventions: explanation and elaboration. BMJ. 2009;339:b2700.

29. Higgins JPT, Altman DG, Gøtzsche PC, Jüni P, Moher D, Oxman AD, et al. The Cochrane Collaboration's tool for assessing risk of bias in randomised trials. BMJ. 2011;343:d5928.

30. European Medicines Agency (EMA). Xeljanz: EPAR product information [Internet]. 2020 [cited 2021 Jan 15]. https://www.ema.europa.eu/en/medicines/ human/EPAR/xeljanz

31. U.S. Food and Drug Administration. XELJANZ® (tofacitinib) tablets: prescribing information [Internet]. 2018 [cited 2019 Oct 8]. http://labeling. pfizer.com/showlabeling.aspx?id=959

32. Dias S, Welton NJ, Sutton AJ, Ades A. NICE DSU Technical Support Document 2: A generalised linear modelling framework for pairwise and network meta-analysis of randomised controlled trials. [Internet]. 2011 [cited 2020 Jan 30]. http://nicedsu. org.uk/wp-content/uploads/2017/05/TSD2-

General-meta-analysis-corrected-2Sep2016v2.pdf

33. Dias S, Sutton AJ, Welton NJ, Ades A. NICE DSU Technical Support Document 3: heterogeneity: subgroups, meta-regression, bias and bias-adjustment [Internet]. 2011 [cited 2020 Jan 31]. http:// nicedsu.org.uk/wp-content/uploads/2016/03/ TSD3-Heterogeneity.final-report.08.05.12.pdf

34. Jansen JP, Fleurence R, Devine B, Itzler R, Barrett A, Hawkins $\mathrm{N}$, et al. Interpreting indirect treatment comparisons and network meta-analysis for healthcare decision making: Report of the ISPOR task force on indirect treatment comparisons good research practices: Part 1. Value Heal. 2011;14: 417-28.

35. Hoaglin DC, Hawkins N, Jansen JP, Scott DA, Itzler $\mathrm{R}$, Cappelleri JC, et al. Conducting indirect-treatment-comparison and network-meta-analysis studies: report of the ISPOR task force on indirect treatment comparisons good research practices: Part 2. Value Heal. 2011;14:429-37. 
36. Kremer JM, Bloom BJ, Breedveld FC, Coombs JH, Fletcher MP, Gruben D, et al. The safety and efficacy of a JAK inhibitor in patients with active rheumatoid arthritis: results of a double-blind, placebocontrolled phase IIa trial of three dosage levels of CP-690,550 versus placebo. Arthritis Rheum. 2009;60:1895-905.

37. Incyte Corporation. INCB028050 compared to background therapy in patients with active rheumatoid arthritis (RA) with inadequate response to disease modifying anti-rheumatic drugs [Internet]. 2018 [cited 2020 May 6]. https://clinicaltrials. gov/ct2/show/NCT00902486

38. Kawalec P, Mikrut A, Wiśniewska N, Pilc A. The effectiveness of tofacitinib, a novel Janus kinase inhibitor, in the treatment of rheumatoid arthritis: a systematic review and meta-analysis. Clin Rheumatol. 2013;32:1415-24.

39. Kunwar S, Collins CE, Constantinescu F. Baricitinib, a Janus kinase inhibitor, in the treatment of rheumatoid arthritis: a systematic literature review and meta-analysis of randomized controlled trials. Clin Rheumatol. 2018;37:2611-20.

40. Winthrop KL, Yamanaka H, Valdez H, Mortensen E, Chew R, Krishnaswami S, et al. Herpes zoster and tofacitinib therapy in patients with rheumatoid arthritis. Arthritis Rheumatol. 2014;66:2675-84.

41. van der Heijde D, Tanaka Y, Fleischmann R, Keystone E, Kremer J, Zerbini C, et al. Tofacitinib (CP$690,550)$ in patients with rheumatoid arthritis receiving methotrexate: twelve-month data from a twenty-four-month phase III randomized radiographic study. Arthritis Rheum. 2013;65:559-70.

42. Takeuchi T, Yamanaka H, Yamaoka K, Arai S, Toyoizumi S, DeMasi R, et al. Efficacy and safety of tofacitinib in Japanese patients with rheumatoid arthritis by background methotrexate dose: a post hoc analysis of clinical trial data. Mod Rheumatol. 2019;29:756-66.

43. Kivitz AJ, Gutierrez-Urena SR, Poiley J, Genovese MC, Kristy R, Shay K, et al. Peficitinib, a JAK inhibitor, in the treatment of moderate-to-severe rheumatoid arthritis in patients with an inadequate response to methotrexate. Arthritis Rheumatol. 2017;69:709-19.

44. Genovese MC, Greenwald M, Codding C, Zubrzycka-Sienkiewicz A, Kivitz AJ, Wang A, et al. Peficitinib, a JAK inhibitor, in combination with limited conventional synthetic disease-modifying antirheumatic drugs in the treatment of moderate-tosevere rheumatoid arthritis. Arthritis Rheumatol. 2017;69:932-42.
45. Takeuchi T, Tanaka Y, Iwasaki M, Ishikura H, Saeki S, Kaneko Y. Efficacy and safety of the oral Janus kinase inhibitor peficitinib (ASP015K) monotherapy in patients with moderate to severe rheumatoid arthritis in Japan: a 12-week, randomised, doubleblind, placebo-controlled phase IIb study. Ann Rheum Dis. 2016;75:1057-64.

46. Fleischmann RM, Van Der Heijde D, Gardiner PV, Szumski A, Marshall L, Bananis E. DAS28-CRP and DAS28-ESR cut-offs for high disease activity in rheumatoid arthritis are not interchangeable. RMD Open. 2017;3:e000382.

47. Smolen JS, Landewé RBM, Bijlsma JWJ, Burmester GR, Dougados M, Kerschbaumer A, et al. EULAR recommendations for the management of rheumatoid arthritis with synthetic and biological disease-modifying antirheumatic drugs: 2019 update. Ann Rheum Dis. 2020;79:685-99.

48. Atsumi T, Yamamoto $\mathrm{K}$, Takeuchi T, Yamanaka $\mathrm{H}$, Ishiguro N, Tanaka $\mathrm{Y}$, et al. The first double-blind, randomised, parallel-group certolizumab pegol study in methotrexate-naïve early rheumatoid arthritis patients with poor prognostic factors, C-OPERA, shows inhibition of radiographic progression. Ann Rheum Dis. 2016;75:75-83.

49. Nishimoto N, Hashimoto J, Miyasaka N, Yamamoto K, Kawai S, Takeuchi T, et al. Study of active controlled monotherapy used for rheumatoid arthritis, an IL-6 inhibitor (SAMURAI): evidence of clinical and radiographic benefit from an $\mathrm{x}$ ray readerblinded randomised controlled trial of tocilizumab. Ann Rheum Dis. 2007;66:1162-7.

50. Takeuchi T, Miyasaka N, Zang C, Alvarez D, Fletcher $\mathrm{T}$, Wajdula $\mathrm{J}$, et al. A phase 3 randomized, doubleblind, multicenter comparative study evaluating the effect of etanercept versus methotrexate on radiographic outcomes, disease activity, and safety in Japanese subjects with active rheumatoid arthritis. Mod Rheumatol. 2013;23:623-33.

51. Yamamoto K, Takeuchi T, Yamanaka H, Ishiguro N, Tanaka Y, Eguchi K, et al. Efficacy and safety of certolizumab pegol without methotrexate co-administration in Japanese patients with active rheumatoid arthritis: the HIKARI randomized, placebo-controlled trial. Mod Rheumatol. 2014;24: 552-60.

52. Tanaka Y, Suzuki M, Nakamura H, Toyoizumi S, Zwillich SH. Phase II study of tofacitinib (CP$690,550)$ combined with methotrexate in patients with rheumatoid arthritis and an inadequate response to methotrexate. Arthritis Care Res. 2011;63:1150-8.

53. Van Vollenhoven RF, Fleischmann R, Cohen S, Lee EB, Meijide JAG, Wagner $S$, et al. Tofacitinib or 
adalimumab versus placebo in rheumatoid arthritis. N Engl J Med. 2012;367:508-19.

54. Fleischmann R, Cutolo M, Genovese MC, Lee EB, Kanik KS, Sadis S, et al. Phase IIb dose-ranging study of the oral JAK inhibitor tofacitinib (CP-690,550) or adalimumab monotherapy versus placebo in patients with active rheumatoid arthritis with an inadequate response to disease-modifying antirheumatic drugs. Arthritis Rheum. 2012;64:617-29.

55. Kremer JM, Cohen S, Wilkinson BE, Connell CA, French JL, Gomez-Reino J, et al. A phase IIb doseranging study of the oral JAK inhibitor tofacitinib (CP-690,550) versus placebo in combination with background methotrexate in patients with active rheumatoid arthritis and an inadequate response to methotrexate alone. Arthritis Rheum. 2012;64: 970-81.

56. Fleischmann R, Kremer J, Cush J, Schulze-Koops H, Connell CA, Bradley JD, et al. Placebo-controlled trial of tofacitinib monotherapy in rheumatoid arthritis. N Engl J Med. 2012;367:495-507.

57. Burmester GR, Blanco R, Charles-Schoeman C, Wollenhaupt J, Zerbini C, Benda B, et al. Tofacitinib (CP-690,550) in combination with methotrexate in patients with active rheumatoid arthritis with an inadequate response to tumour necrosis factor inhibitors: a randomised phase 3 trial. Lancet. 2013;381:451-60.

58. Kremer J, Li ZG, Hall S, Fleischmann R, Genovese M, Martin-Mola E, et al. Tofacitinib in combination with nonbiologic disease-modifying antirheumatic drugs in patients with active rheumatoid arthritis: a randomized trial. Ann Intern Med. 2013;159: 253-61.

59. Tanaka Y, Takeuchi T, Yamanaka H, Nakamura $H$, Toyoizumi S, Zwillich S. Efficacy and safety of tofacitinib as monotherapy in Japanese patients with active rheumatoid arthritis: a 12-week, randomized, phase 2 study. Mod Rheumatol. 2015;25: 514-21.

60. Keystone EC, Taylor PC, Drescher E, Schlichting DE, Beattie SD, Berclaz PY, et al. Safety and efficacy of baricitinib at 24 weeks in patients with rheumatoid arthritis who have had an inadequate response to methotrexate. Ann Rheum Dis. 2015;74:333-40.

61. Tanaka Y, Emoto K, Cai Z, Aoki T, Schlichting D, Rooney $\mathrm{T}$, et al. Efficacy and safety of baricitinib in Japanese patients with active rheumatoid arthritis receiving background methotrexate therapy: a 12-week, double-blind, randomized placebo-controlled study. J Rheumatol. 2016;43:504-11.

62. Genovese MC, Kremer J, Zamani O, Ludivico C, Krogulec M, Xie L, et al. Baricitinib in patients with refractory rheumatoid arthritis. $\mathrm{N}$ Engl J Med. 2016;374:1243-52.

63. Taylor PC, Keystone EC, Van Der Heijde D, Weinblatt ME, Del Carmen ML, Gonzaga JR, et al. Baricitinib versus placebo or adalimumab in rheumatoid arthritis. N Engl J Med. 2017;376: 652-62.

64. Dougados M, Van Der Heijde D, Chen Y-CC, Greenwald M, Drescher E, Liu J, et al. Baricitinib in patients with inadequate response or intolerance to conventional synthetic DMARDs: results from the RA-BUILD study. Ann Rheum Dis. 2017;76:88-95.

65. Eli Lilly and Company. A Study of baricitinib (LY3009104) in participants with rheumatoid arthritis (RA) [Internet]. 2019 [cited 2020 May 6]. https://www.clinicaltrials.gov/ct2/show/ NCT02265705 